\title{
Interconnectedness between Commodity Futures and Spot Prices: A Comparative Analysis between Ordinary Least Square (OLS) and Quantile Regression (QR)
}

\author{
Cosmos Amoah 10 \\ Department of Finance, School of Business, University of Cape Coast, Cape Coast, Ghana \\ Email: cosmos.amoah@stu.ucc.edu.gh
}

How to cite this paper: Amoah, C. (2021). Interconnectedness between Commodity Futures and Spot Prices: A Comparative Analysis between Ordinary Least Square (OLS) and Quantile Regression (QR). Technology and Investment, 12, 151-167. https://doi.org/10.4236/ti.2021.123009

Received: May 17, 2021

Accepted: July 26, 2021

Published: July 29, 2021

Copyright $\odot 2021$ by author(s) and Scientific Research Publishing Inc. This work is licensed under the Creative Commons Attribution International License (CC BY 4.0).

http://creativecommons.org/licenses/by/4.0/

\begin{abstract}
The study sought to contribute to the extant literature on the interconnectedness between commodity spot prices and futures prices by covering daily data from 2001-2019. Employing the OLS and the QR, different dynamics of the relationship between commodity spot and futures prices emerged from the study. For oil and gold prices, OLS estimator revealed that neither spot nor futures prices of the commodities had a significant effect on the other. Quantile regression estimators however suggested otherwise. For oil prices, futures prices were found to have a significant positive effect on spot oil prices at the $60^{\text {th }}$ and $75^{\text {th }}$ percentile whereas spot oil prices were found to have a significant positive effect on the futures oil prices at the lower tail $(0.1,0.2$, and 0.25 quantiles). For gold prices, futures gold prices had a significant positive effect on spot gold prices at the $75^{\text {th }}$ percentile ( $3^{\text {rd }}$ quantile) marked as the upper tail of the distribution whereas a significant negative effect was revealed at the middle quantile ( $50^{\text {th }}$ percentile). For cocoa prices, both the OLS and the QR estimators were significant in either direction. A significant positive effect of futures (spot) cocoa price on spot (futures) cocoa price was observed across all quantiles in both directions. The results suggest that speculators and arbitrageurs in the commodity market must be concerned about the causality moving from one direction to another and take appropriate investment positions that protect their interests.
\end{abstract}

\section{Keywords}

Spot Prices, Futures Prices, Interconnectedness, Quantile, Normality, Linearity 


\section{Introduction}

Market participants and traders in currency and commodity markets have remained concerned about the importance, differences, and trade implications meted out by the arguments surrounding spot prices and futures prices in price discovery and price determination. To this end, the causal link between commodity spot and futures market has remained debatable and inconclusive. The nature of uncertainty surrounding the commodity market facilitates policy discussion about the reasons for commodity price fluctuations (Alzahrani, Masih, \& Al-Titi, 2014). Attempting to resolve the debate surrounding futures and spot prices would direct various economic agents to make the right choices (Samak, Hosni, \& Kamal, 2020).

Earlier researches have revealed different strands of findings on the co-movement between spot and futures prices. The following pieces of literature adduce shreds of evidence to suggest that commodity futures prices cause commodity spot prices (Silvapulle \& Moosa, 1999; Moosa \& Al-Loughani, 1995) for the following reasons: that futures prices adapt to new news more quickly than spot prices; that futures are more susceptible to market manipulations and; that futures serve as guideposts for speculators and arbitrageurs.

Contrarily, (Moosa, 2002; Quan, 1992) shares, in a spot prices-futures prices modelling, evidence of spot prices leading futures prices on the assumption that speculators and arbitrageurs rely on spot prices as a point of reference in engaging in futures markets activities. Other authors opine that there is a bi-causal interconnection between spot prices and futures prices (Alzahrani, Masih, \& Al-Titi, 2014; Kaufmann \& Ullman, 2009; Bekiros \& Diks, 2008).

Despite the glaringly numerous contradictions in the results generated for the relationship between spot prices and futures prices in the commodity market and other financial markets, works of literature to some extent have agreed that there is a long-term relationship between spot prices and futures prices (Kawamoto \& Hamori, 2011; In \& Kim, 2006; Chen \& Lin, 2004; Fong \& See, 2003). The contradictory findings can be attributed to the following reasons: the type of contract used, the sample period for data, and the modelling approach.

A brazen alignment of research interest in this concept is particularly necessary for market efficiency analysis and investment decisions. Zavadska, Morales and Coughlan (2018) hold that spot prices seem to be affected mainly by demand and supply, and the prevailing level of economic activity. In furtherance, they assert that analysing the nexus and the lead-lag relationship between spot prices and futures prices sheds enough light on the important dispositions for investors and stakeholders who want to forecast prices trends and behaviour. They opine further that understanding the lead-lag interconnections between spot and futures prices offer economic players the opportunity to appreciate the influence of shocks on the interaction and to provide the necessary hedging strategies.

As a contribution to the extant literature, and finessing the problems that have contributed to the differing results that have emerged over the topic, the study 
sheds a deeper light on the interactive linkages between commodity futures and spot prices by employing a more robust technique for analysis. As a consequence of the above, a significant contribution of the study despite presenting a side-byside narrative of the results and findings from two different techniques which are unnoticeable in previous studies is the deflection from the usual use of oil prices and expanding the coverage and scope of variables to capture prices of gold and cocoa which are an indispensable part of the world's commodity market.

In this study, Ordinary Least Square (OLS) and Quantile Regression (QR) are used to simultaneous estimate the relationship between futures and spot prices. In more particular, $\mathrm{QR}$ is given more attention since pieces of literature have provided evidence of superiority over OLS. QR helps to uncover possible relationships and co-movement between futures and spots at different quantile spate thus providing a deeper understanding of the nexus. Quantile regression also aids in comprehensively describing the conditional distribution of the explained variables, rather than simply analysing the conditional expectation of the explained variable. Again, quantile regression harnesses a more robust estimated result.

The remainder of this article is structured as follows: Section 2 provides brief but concise works of literature on the co-movement between commodity futures and spot prices. Section 3 deals with the research methods and framework adopted for the study. Whereas section 4 elaborates the empirical results of the study, section 5 provides the conclusion for the research.

\section{Literature Review}

\subsection{Theoretical Basis}

The relationship between futures and spot prices has been underpinned theoretically. The reviewed theories that underpin the study are the Cost of Carry Model (Kaldor, 1939; Working, 1949), and the Arbitrage Pricing Theory (Fama, 1970).

Markets are assumed to be perfectly efficient in the Cost of Carry Model. This signifies that the cash and futures prices are the same. As a result, arbitrage-the practice of traders taking advantage of price disparities in two or more marketsbecome an ineffective option (Lian, Cheng, Lin, \& Lin, 2019). The theory describes the relationship between futures and spot as:

$$
F_{t}^{T} \geq S_{t} \mathrm{e}^{(r+c-y)(T-t)}
$$

where $F_{t}^{T}$ is the future price at the time $t$ for a contract expiring at time $T, S_{t}$ as the spot price at time $t, r$ is the risk-free rate, $c$ is the storage cost, and $y$ is the convenience yield. To avoid arbitrage opportunities, the interconnection between spot and futures should hold (Alzahrani, Masih, \& Al-Titi, 2014).

Also, Arbitrage Pricing Model which is based on the Efficient Market Hypothesis opines that futures prices are unbiased predictors of spot prices such that markets are efficient and risk premiums are absent (Samak, Hosni, \& Kamal, 2020; Fama, 1970). The relationship is described as: 


$$
F_{t}^{T}-S_{t}=E_{t}\left[S_{T}-S_{t}\right]
$$

\subsection{Empirical Relationship between Spot Prices and Futures Prices}

Studies have produced interesting results and findings on the relationship between commodity prices and exchange rate. In those studies, different strands and dynamics of interdependence and co-movement have emerged. The following studies have suggested evidence of co-movement between commodity prices and exchange rate in either direction. Among the currently existing literature, evidence of bi-causality has been agreed upon.

Manogna \& Mishra (2020) studied the price discovery and volatility spillover from spot and futures agricultural commodity markets in India. With data from 2003 to 2019 and employing a Granger causality test, the results revealed that movement of the futures market has the greatest ability to predict spot market prices. Similarly, Inani (2018), and Ali and Gupta (2011) confirm the ability of futures prices to lead spot prices in a price discovery analysis.

Junior, Tiwari, Padhan and Alagidede (2020) analysed the spot and futures nexus from noise-free modelling by employing the ensemble empirical mode decomposition based quantile-on-quantile regression approach. Employing daily data from 2005 to 2016, their empirical study revealed instances of weak to very strong dependencies across both positive and negative spheres of different quantiles.

Similar to Junior et al. (2020), Gil-Alana, Martin-Valmayor and Wanke (2020) carried out an investigation with a denoising technique "fractional integration" for Spain and Portugal for the period 2007-2017. They observed that there are moderate to weak correlations between commodity spots and futures energy markets. Additionally, they observed that all the series are fractionally integrated, indicating a long memory and mean reverting behaviour.

Miljkovic and Goetz (2020) examined the extent to which futures markets stabilises and/or destabilize spot oil prices in both the short and long run time horizon. The empirical result indicates that spot oil prices are destabilized in the short run and stabilised in the long run, and this is attributed to the dynamics of the futures market.

$\mathrm{Xu}$ (2018) investigates the causal structure among Chicago Board of Trade corn futures prices and seven regional spot prices. Employing wavelet approach as a test for causality, daily data was sampled from January 2006 to March 2011. Empirical findings suggested that for timescale below one month, there was no causality between futures prices and spot prices. However, for timescale greater than one month but less than 12 months, a bi-directional interconnection was determined among all prices. Also, beyond 12 months, no interstate causality was found.

Polanco-Martinez and Abadie (2016) examined in a wavelet analysis approach, the interconnectedness between crude oil spot price and long-term futures prices. A daily data span from February 2006 to April 2016 was used. The findings from the study suggested, like Alzahrani, Masih and Al-Titi (2014), a bidirectional 
causality evolved from the study. More particularly, a bi-causal relationship was revealed for intra-week, weekly, fortnightly, and bi-annual scales showing that both markets react concurrently to market externalities in those timescale.

Wang and $\mathrm{Wu}$ (2012) examined the long run co-movement between oil spot prices and futures prices. Using weekly, monthly and quarterly data from 1986 to 2011, their results indicated, from a Johansen cointegration and VECM models, evidence of long run bi-causal relationship between spot and futures. Similar studies corroborate with their findings and point out that there is long run association between spot and futures markets (Zhang \& Wang, 2013; Mamatzakis \& Remoundos, 2011).

Lee and Zeng (2011) studied the relationship between spot and futures oil prices using a quantile cointegrating regression approach of time series analysis. With data from 1986 to 2009, their empirical analysis revealed that spot oil prices response to shocks in futures oil prices. Further to this, the study indicated that the response is steeper and stronger at high spot prices compared to response at low spot prices.

Generally, it is clear from the empirical studies above that several researches have concluded on diverse result in the spot-futures nexus. Again, extant of literature have concentrated on oil market at the expense of varied commodities. To this extent, this study looked at spot-futures nexus for cocoa, oil and the 11:30am versus 3:00pm gold prices for a relatively broader data span, 2001 to 2019.

\section{Data and Methodology}

\subsection{Data}

The analysis of the study was conducted using data from the following sources. Daily oil prices measured in USD per barrel, both futures and spot, were obtained from WTI at the US Energy Information Administration website. In particular, the futures prices used in the study were a one-month maturity contract. Daily cocoa prices were obtained from the International Cocoa Organisation's website. Daily cocoa prices were also measured in USD per metric tonne. Finally, daily gold prices, measured as USD per troy ounce, were obtained from the London Market Bullion Association's website. Data were sampled from 2001 to 2019. On days where prices are missing in all markets, the observation is omitted and an assumption of smooth continuity is made. The data were transformed to logreturns to meet the stationarity test. Data transformation was estimated as follows:

$$
R_{t}=\operatorname{Ln}\left(P_{t+1}\right) / \operatorname{Ln}\left(P_{t}\right)
$$

\subsection{Methodology}

Given the intended objective of the study and the need to provide clear and robust insight into the relationship between commodity futures and spots, the quantile regression technique was employed. According to Eide and Showalter 
(1998), quantile regression is a robust regression technique that enables the estimation of the effects of predictor variables on the outcome variable at different points of dependent variables conditional distribution. To this end, quantile regression has been proffered as superior to ordinary least square (OLS) method. The application of quantile regression to regression models helps to get rid of biased estimates that are created when OLS is used (Le \& Nguyen, 2020; Zietz, Zietz, \& Sirmans, 2008).

Arguing further, Zietz, Zietz and Sirmans state that quantile regression is based on the minimisation of weighted absolute deviations to estimate conditional quantile functions unlike the classical OLS estimates of conditional mean functions., that is, quantile regression is not only about explaining the mean of the regressand but also the determinant of the regressand at any point of its distribution. Pham and Vo (2021), as well as Baker, Pham, Daniel and Bentley (2020), also add to the argument in favour of quantile regression over OLS. They argue that quantile regression estimators are not susceptible to outliers as such it is capable of revealing the importance of differences distributional results.

\subsection{Ordinary Least Square (OLS)}

Ordinary Least Square is widely used to estimate the parameters of linear regression based on the conditional mean functions. The study used OLS because assumptions of linearity (BDS test) and normality (Jarque-Bera test, Kolmogorov Smirnoff and Shapiro-Wilk) were met. The model is thus defined as:

$$
\operatorname{LnRt}(S, F)_{t}=\alpha+\beta_{t} \operatorname{Ln} R t(S, F)_{t}+\varepsilon_{t}
$$

where $\operatorname{Ln} R t(S, F)_{t}$ denote log-returns of spot $(S)$ prices and futures $(F)$ prices, $\alpha$ denote a constant term and $\varepsilon_{t}$ denote the error term and $\beta_{t}$ denote the coefficient value. The error term is not clustered since treatment is not assigned at the level of a cluster.

\subsection{Quantile Regression Model (QRM)}

Alternative to the Ordinary Least Square approach, the study employs the quantile regression approach proposed by Koenker and Bassett (1978). According to Firpo, Galvao and Song (2017) as well as Lee and Zeng (2011), quantile regression, unlike the traditional OLS, allows researchers to exploit cointegrating relationship between futures and spot prices by assessing the time-varying coefficients available through the quantiles. As suggested by (Kodila-Tedika \& Bolito-Losembe, 2014; Hao \& Naiman, 2007), using OLS may produce biased estimates and this problem can be finessed by employing quantile regression which is based on a minimisation function. Quantile regression minimizes a weighted sum of the absolute deviations (Zietz, Zietz, \& Sirmans, 2008). This is given as:

$$
\min \sum_{i}\left|y_{i}-\sum_{j=0}^{k} b_{j} x_{j, i}\right| h_{i}
$$

where the weight $h_{i}$ is defined as

$$
h_{i}=2 q
$$

If the residual for the $i$ th observation is strictly positive or as 


$$
h_{i}=2-2 q
$$

If the residual for the $i$ th observation is negative or zero, the variable $q[0<q<1]$ is the quantile to be estimated.

Following the work of Pham and Vo (2021) and subsequently adopting their model, quantile regression estimator is described as:

$$
\beta_{Q R}=\arg \min \left[\sum_{Y_{i}>B X_{i}} \tau\left|Y_{i}-B X_{i}\right|+\sum_{Y_{i}<B X_{i}}(1-\tau)\left|Y_{i}-B X_{i}\right|\right], \forall \tau \in(0,1)
$$

\section{Results and Discussions}

This section provides the results that emanated from the study. Whereas the first part presents preliminary results including descriptives, ADF, KPSS, normality test, and BDS test, the second discusses the empirical results based on the quantile regression.

\subsection{Preliminary Analysis}

Table 1 also presents the results of the test of stationarity in the series. From the $\mathrm{ADF}$ test, which is premised on the null hypothesis that the data is non-stationary, the null hypothesis is rejected as all the $p$-values are less than 0.05 . Also, from the KPSS test, which is premised on the null hypothesis that the data is stationary, the null hypothesis cannot be rejected as all the t-stat values are less than the critical values at $5 \%$. As such, the conclusion is that the data is stationary when the log-returns transformation was done.

Table 2 presents test results ( $p$-values) on the null hypothesis that data was sampled from a normal distribution. From the result entries in Table 3, Kolmogorov-Smirnov, Jarque-Bera and Shapiro-Wilk tests failed to reject the null hypothesis and conclude that the series (log returns) are normally distributed. After this test results are the pictorial evidence displayed in the histograms of the log-returns of the variables in Figures 1-6. The normality test for the raw data showed that the data was not normality. To conclude, the data exhibited normal distribution when log-returns were calculated.

Figures 1-6 show the distribution of the log-returns of the variables. The figures confirm the tests by Jarque Bera and Shapiro-Wilk which assert that the data is normally distributed.

Table 3 presents the test results ( $p$-values) of the Brock, Dechert and Scheinkman (1987) test of linearity. From Table 1, the test fails to reject the null hypothesis that the series are linearly dependent. This comes after the BDS test rejected the null hypothesis for the raw untransformed data. The conclusion is that the data in the raw state is non-linear but becomes linear after log-returns were calculated.

Table 4 presents the summary statistics for the variables. It can be observed from the displayed results that on the mean average spot cocoa had the highest daily price and spot oil recording the lowest mean average daily price. The maximum value represents the highest price for a particular series whereas the minimum value represents the lowest price for a particular series. 
Histogram of Futures.cocoa

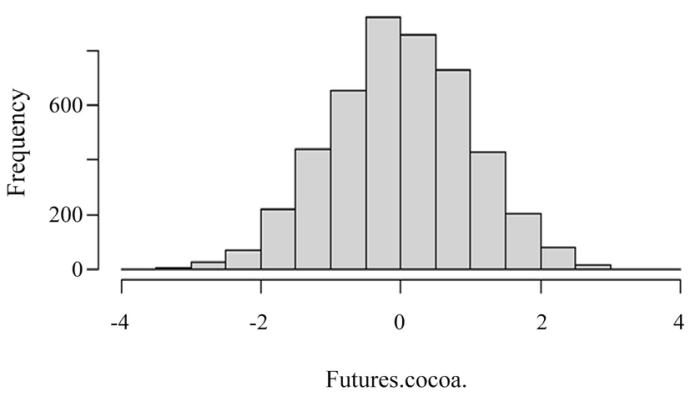

Figure 1. Histogram of log returns of futures cocoa prices.

Histogram of Futures.Gold.

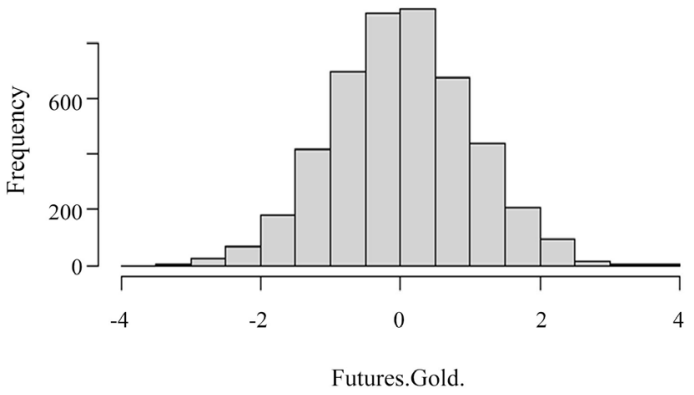

Figure 2. Histogram of log returns of futures gold prices.

Histogram of Futures.Oil.

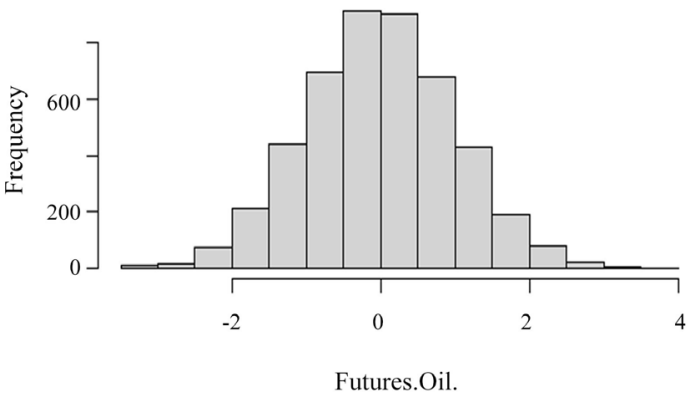

Figure 3. Histogram of log returns of futures oil prices.

Histogram of Spot.cocoa.

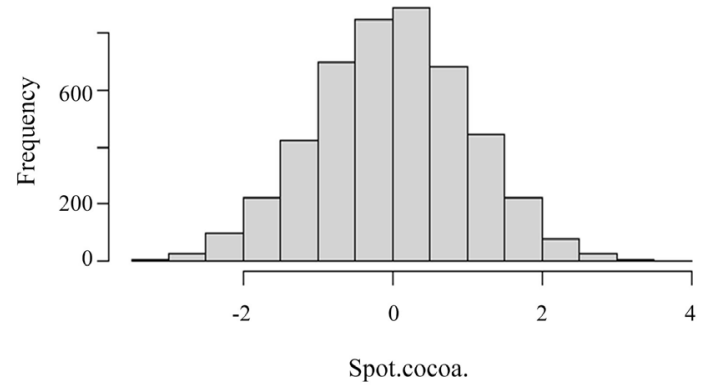

Figure 4. Histogram of log returns of spot cocoa prices. 
Histogram of Spot.gold.

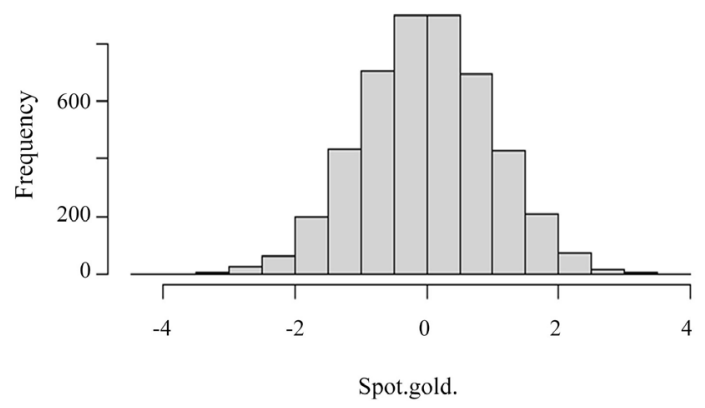

Figure 5. Histogram of log returns of spot gold prices.

Histogram of Spot.Oil.

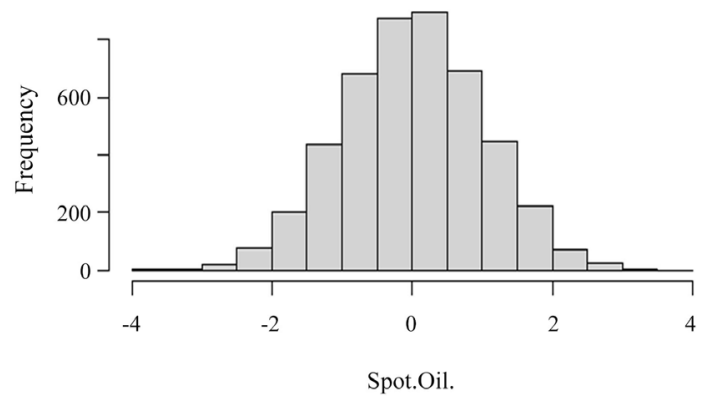

Figure 6. Histogram of log returns of spot oil prices.

Table 1. Result for Unit root test.

\begin{tabular}{ccccc}
\hline \multicolumn{2}{c}{ Augmented Dickey-Fuller $(A D F)$ Test } & \multicolumn{2}{c}{ KPSS Test } \\
\hline $\mathrm{v}$ & $p$-value & t-statistics & critical value at 5\% & t-statistics \\
\hline FC & $<2.2 \mathrm{e}-16^{* * *}$ & 47.689 & 0.146 & 0.0625 \\
SC & $<2.2 \mathrm{e}-16^{* * *}$ & 47.578 & 0.146 & 0.1027 \\
FG & $<2.2 \mathrm{e}-16^{* * *}$ & 47.466 & 0.146 & 0.0193 \\
SG & $<2.2 \mathrm{e}-16^{* *}$ & 48.183 & 0.146 & 0.0301 \\
FO & $<2.2 \mathrm{e}-16^{* *}$ & 48.263 & 0.146 & 0.0514 \\
SO & $<2.2 \mathrm{e}-16^{* * *}$ & 48.044 & 0.146 & 0.0525 \\
\hline
\end{tabular}

Note: FC represents futures cocoa prices, SC as spot cocoa, FG as futures gold price, SG as spot gold price, $\mathrm{FO}$ as futures oil prices and SO as spot oil prices, Significance level is $5 \%$ or $p$-value less than or equals 0.05 , significance codes: 0 “***”, 0.001 “**”, 0.01 “*”, 0.05 “.”, 0.1 “”. KPSS means Kwiatkowski-PhilipsSchmidt-Shin Test of stationarity.

Table 2. Normality Test on Log-returns of the variable ( $p$-values).

\begin{tabular}{ccccccc}
\hline Test & FC & SC & FG & SG & FO & SO \\
\hline JB & 0.2337 & 0.8510 & 0.4654 & 0.4261 & 0.7016 & 0.6431 \\
SW & 0.6714 & 0.7668 & 0.8835 & 0.8212 & 0.8440 & 0.5528 \\
KS & 0.4751 & 0.8420 & 0.8383 & 0.3572 & 0.6844 & 0.4988 \\
\hline
\end{tabular}

Note: FC represents futures cocoa prices, SC as spot cocoa, FG as futures gold price, SG as spot gold price, $\mathrm{FO}$ as futures oil prices and SO as spot oil prices, Significance level is $5 \%$ or $p$-value less than or equals 0.05 , significance codes: 0 “***”, 0.001 “**”, 0.01 “*”, 0.05 “.”, 0.1 “”. JB means Jarque-Bera Test, KS denotes Kolmogorov-Smirnov Test, and SW means Shapiro-Wilk Test for normality. 
Table 3. BDS test of linearity (Log returns of Variables).

\begin{tabular}{ccccccc}
\hline$(\mathrm{m})$ & FC & SC & FG & SG & FO & SO \\
\hline 2 & 0.9157 & 0.6535 & 0.3040 & 0.3226 & 0.0480 & 0.4666 \\
3 & 0.5273 & 0.6577 & 0.4587 & 0.3966 & 0.0173 & 0.1183 \\
4 & 0.2685 & 0.9796 & 0.6016 & 0.2859 & 0.0422 & 0.0768 \\
5 & 0.3029 & 0.8949 & 0.6364 & 0.1651 & 0.6392 & 0.1276 \\
6 & 0.2377 & 0.6583 & 0.8937 & 0.1946 & 0.6392 & 0.1732 \\
\hline
\end{tabular}

Note: $m$ denotes the embedding dimension of the BDS, FC represents futures cocoa prices, SC as spot cocoa, FG as futures gold prices, SG as spot gold prices, FO as futures oil price and SO as spot oil prices, the significance level is $5 \%$ or $p$-value less than or equals 0.05 , significance codes: 0 “***», 0.001 “**”, 0.01 “*”, 0.05 “., 0.1 “”.

Table 4. Descriptive statistics on raw data (In USD).

\begin{tabular}{ccccccc}
\hline v & Mean & Median & SD & Max & Min & N \\
\hline FC & 2244.00 & 2260.00 & 638.65 & 3633.00 & 778 & 4661 \\
SC & 2281.10 & 2250.70 & 648.16 & 3698.80 & 823.60 & 4661 \\
FG & 972.80 & 1122.30 & 460.97 & 3094.30 & 256.70 & 4661 \\
SG & 969.80 & 1126.50 & 450.88 & 1895.00 & 255.95 & 4661 \\
FO & 63.58 & 60.32 & 25.82 & 145.29 & 17.45 & 4661 \\
SO & 63.53 & 60.15 & 25.83 & 145.31 & 17.50 & 4661 \\
\hline
\end{tabular}

Note: FC represents Futures cocoa prices, SC as spot cocoa, FG as futures gold price, SG as spot gold price, FO as futures oil prices and SO as spot oil prices, SD denotes Standard Deviation, Max denotes maximum value, Min denotes Minimum value, $\mathrm{N}$ denotes the number of observations and V denotes variable.

\subsection{Empirical Results}

This section presents the results of the study.

From Table 5 and Table 6, evidence of a significant relationship between futures and spot prices are revealed at different quantile marks. From Table 5, using oil futures as a predictor variable and spot oil prices as the independent variable, evidence of a significant relationship was observed just after the middle quantile (from the $60^{\text {th }}$ percentile as well as the $75^{\text {th }}$ percentile) at a $p$-value of 0.00094 and 0.03317 less than 0.05 . The result suggests that up to oil within futures prices within the $60^{\text {th }}$ and $75^{\text {th }}$ percentile can predict spot prices, however below and above the $60^{\text {th }}$ and $75^{\text {th }}$ percentile, oil futures is unable to predict spot prices. This is marked as the years leading to 2015 .

From Table 6, spot oil prices were found to be significant in predicting futures at the lower quartiles. From the $10^{\text {th }}$ percentile to the $25^{\text {th }}$ percentile, spot prices could influence futures oil prices beyond which it becomes insignificant in predicting futures oil prices. This was specifically observed in the years to 2005 . The result from Table 5 and Table 6 differ from the OLS outcome (in Table 7) which outrightly fails to reject the null hypothesis of no relationship between spot prices and futures prices for oil in either direction. 
Table 5. Quantile regression of futures oil prices on spot oil prices.

\begin{tabular}{cccc}
\hline Quantiles & B (Coefficient value) & S. E & $p$-values \\
\hline 0.1 & 0.02542 & 0.02820 & 0.36741 \\
0.2 & 0.02997 & 0.01872 & 0.10954 \\
0.25 & 0.02840 & 0.01802 & 0.11514 \\
0.5 & 0.02329 & 0.01385 & 0.09270 \\
0.6 & $0.04150^{* * *}$ & 0.01253 & 0.00094 \\
0.75 & $0.03744^{*}$ & 0.01757 & 0.03317 \\
0.8 & 0.02427 & 0.01769 & 0.17007 \\
0.9 & 0.03956 & 0.02585 & 0.12598 \\
0.95 & 0.02741 & 0.03807 & 0.47149 \\
\hline
\end{tabular}

significance level is $5 \%$ or $p$-value less than or equals 0.05 , significance codes: 0 “***», 0.001 “**», 0.01 “*”, 0.05 “.”, 0.1 "”. S. E denotes standard error, B denotes Beta.

Table 6. Quantile regression of spot oil prices on futures oil prices.

\begin{tabular}{cccc}
\hline Quantiles & B (Coefficient value) & S. E & $p$-values \\
\hline 0.1 & $0.05899^{*}$ & 0.02801 & 0.03527 \\
0.2 & $0.05322^{\star *}$ & 0.01834 & 0.00372 \\
0.25 & $0.06623^{* * *}$ & 0.01522 & 0.00001 \\
0.5 & 0.01971 & 0.01232 & 0.10976 \\
0.6 & 0.00842 & 0.01140 & 0.46025 \\
0.75 & -0.00966 & 0.01706 & 0.57144 \\
0.8 & -0.01928 & 0.01670 & 0.24853 \\
0.9 & -0.01491 & 0.02539 & 0.55714 \\
0.95 & -0.02785 & 0.03340 & 0.40445 \\
\hline
\end{tabular}

Significance level is $5 \%$ or $p$-value less than or equals 0.05 , significance codes: 0 “***», 0.001 “**», 0.01 “*”, 0.05 “.”, 0.1 "”. S. E denotes standard error, B denotes Beta.

Table 7. Quantile regression of futures gold prices on spot gold prices.

\begin{tabular}{|c|c|c|c|}
\hline & $\mathrm{B}$ & S. E & $p$-values \\
\hline \multicolumn{4}{|c|}{ Spot oil prices as a Dependent variable and Futures oil prices as an Independent Variable } \\
\hline Intercept & 0.0001688 & 0.0003581 & 0.637 \\
\hline Futures.oil & 0.0249661 & 0.0150836 & 0.098 \\
\hline \multicolumn{4}{|c|}{ Futures oil prices as a Dependent Variable and Spot Oil prices as an Independent Variable } \\
\hline Intercept & 0.0001694 & 0.0003477 & 0.626 \\
\hline Spot.oil & 0.0235442 & 0.0142246 & 0.098 \\
\hline
\end{tabular}

Significance level is $5 \%$ or $p$-value less than or equals 0.05 , significance codes: 0 “***», 0.001 “**», 0.01 “*», 0.05 “”, 0.1 “". S. E denotes standard error, B denote Beta.

Table 8 and Table 9 provide results for quantile regressions and Table 10 displays result for the Ordinary Least Square test for the interconnectedness between futures gold and spot gold prices. From Table 8, it was observed that, at the $50^{\text {th }}$ and $75^{\text {th }}$ percentiles, futures gold prices were relevant and significant in predicting spot gold prices. This suggests that in the years leading to 2010 and 2015 respectively, futures gold prices had a significant association with spot gold 
prices. The null hypothesis of no relationship cannot be rejected for the years beyond 2015.

It is revealed from Table 9 that spot gold prices were significant in predicting futures gold prices in the lower tail (Lower quantile), specifically at the $10^{\text {th }}$ percentile. This denotes that, at the earliest part of the sampled period, marked 2001 to 2002 , spot gold prices affected the futures gold prices movements for the gold market.

Table 8. Quantile regression of futures gold prices on spot gold prices.

\begin{tabular}{cccc}
\hline Quantiles & B & S. E & $p$-values \\
\hline 0.1 & -0.01023 & 0.00745 & 0.16973 \\
0.2 & -0.00489 & 0.00363 & 0.17789 \\
0.25 & -0.00322 & 0.00417 & 0.44022 \\
0.5 & $-0.00176^{*}$ & 0.00073 & 0.01573 \\
0.6 & -0.00053 & 0.00304 & 0.86269 \\
0.75 & $0.00302^{* * *}$ & 0.00060 & 0.00000 \\
0.8 & 0.00272 & 0.00243 & 0.26319 \\
0.9 & -0.00449 & 0.00693 & 0.51671 \\
0.95 & 0.00205 & 0.00885 & 0.81718 \\
\hline
\end{tabular}

Note: significance level is $5 \%$ or $p$-value less than or equals 0.05 , significance codes: 0 “***”, 0.001 “**”, 0.01 “»”, 0.05 “., 0.1 “”. S. E denotes standard error, B denote Beta.

Table 9. Quantile regression of spot gold prices on futures gold prices.

\begin{tabular}{cccc}
\hline Quantiles & B & S. E & $p$-values \\
\hline 0.1 & $-0.07012^{\star * \star}$ & 0.02069 & 0.00071 \\
0.2 & -0.01247 & 0.01570 & 0.42730 \\
0.25 & 0.00078 & 0.01559 & 0.95989 \\
0.5 & 0.01154 & 0.01401 & 0.41032 \\
0.6 & -0.00739 & 0.01398 & 0.59711 \\
0.75 & -0.00140 & 0.01821 & 0.93867 \\
0.8 & 0.00954 & 0.01864 & 0.60897 \\
0.9 & 0.01308 & 0.02851 & 0.64646 \\
0.95 & 0.00190 & 0.05159 & 0.97069 \\
\hline
\end{tabular}

Note: significance level is $5 \%$ or $p$-value less than or equals 0.05 , significance codes: 0 “***», 0.001 “**», 0.01 “»”, 0.05 “., 0.1 “”. S. E denotes standard error, B denote Beta.

Table 10. OLS regression for Gold Prices.

\begin{tabular}{|c|c|c|c|}
\hline & B & S. E & $p$-values \\
\hline \multicolumn{4}{|c|}{ Spot gold prices as an outcome variable and Futures gold prices as a predictor variable } \\
\hline Intercept & $0.0003824^{*}$ & 0.0001635 & 0.0194 \\
\hline Futures.gold & -0.0030740 & 0.0035474 & 0.3862 \\
\hline \multicolumn{4}{|c|}{ Futures gold prices as an outcome variable and Spot gold prices as a predictor variable } \\
\hline Intercept & 0.0004061 & 0.0006757 & 0.548 \\
\hline Spot.gold & -0.0524346 & 0.0605091 & 0.386 \\
\hline
\end{tabular}

Note: significance level is $5 \%$ or $p$-value less than or equals 0.05 , significance codes: 0 “***”, 0.001 “**», 0.01 “»”, 0.05 “., 0.1 “” S. E denotes standard error, B denote Beta. 
From the result displayed in Table 10, the OLS model fails to reject the null hypothesis that there is no relationship between futures gold prices and spot gold prices. This is to conclude that, neither spot prices nor futures gold prices could influence each other entirely. This assertion, however, according to quantile regression is not entirely true. Rather, the two prices could influence each other to some extent.

Table 11 and Table 12 present results on quantile regression for cocoa futures and spot prices whereas Table 13 presents results on the ordinary least square for the same commodity. It is evident from Table 11 and Table 12 that both spot cocoa prices and futures cocoa prices are significant in affecting each other across all the quantiles. The coefficient value is however higher in the middle quantile $\left(50^{\text {th }}\right.$ percentile) through to the $75^{\text {th }}$ percentile as compared to the lower tail and the upper tail represented by the $25^{\text {th }}$ percentile and $95^{\text {th }}$ percentile. Results displayed in Table 13 show that from the ordinary least square test, both spot cocoa prices and futures cocoa prices could predict each other. Evidence of bi-causality is observed.

Table 11. Quantile regression of futures cocoa prices on spot cocoa prices.

\begin{tabular}{cccc}
\hline Quantiles & B & S. E & $p$-values \\
\hline 0.1 & $0.93649^{* * *}$ & 0.00411 & 0.00000 \\
0.2 & $0.93209^{* * *}$ & 0.00320 & 0.00000 \\
0.25 & $0.93325^{* * *}$ & 0.00247 & 0.00000 \\
0.5 & $0.93428^{* * *}$ & 0.00221 & 0.00000 \\
0.6 & $0.93473^{* * *}$ & 0.00237 & 0.00000 \\
0.75 & $0.93967^{* * *}$ & 0.00280 & 0.00000 \\
0.8 & $0.93891^{* * *}$ & 0.00246 & 0.00000 \\
0.9 & $0.93379^{* * *}$ & 0.00304 & 0.00000 \\
0.95 & $0.93467^{* * *}$ & 0.00830 & 0.00000 \\
\hline
\end{tabular}

Significance level is $5 \%$ or $p$-value less than or equals 0.05 , significance codes: 0 “***», 0.001 “**», 0.01 “*”, 0.05 “.”, 0.1 “”. S. E denotes standard error, B denote Beta.

Table 12. Quantile regression of spot cocoa prices on futures cocoa prices.

\begin{tabular}{cccc}
\hline Quantiles & B & S. E & $p$-values \\
\hline 0.1 & $1.02395^{* * *}$ & 0.00553 & 0.00000 \\
0.2 & $1.02930^{* *}$ & 0.00310 & 0.00000 \\
0.25 & $1.03194^{* *}$ & 0.00307 & 0.00000 \\
0.5 & $1.03591^{* *}$ & 0.00222 & 0.00000 \\
0.6 & $1.03765^{* *}$ & 0.00257 & 0.00000 \\
0.75 & $1.03270^{* *}$ & 0.00303 & 0.00000 \\
0.8 & $1.02961^{* *}$ & 0.00295 & 0.00000 \\
0.9 & $1.03032^{* *}$ & 0.00480 & 0.00000 \\
0.95 & $1.02705^{* * *}$ & 0.00749 & 0.00000 \\
\hline
\end{tabular}

Significance level is $5 \%$ or $p$-value less than or equals 0.05 , significance codes: 0 “***», 0.001 “**», 0.01 “*”, 0.05 “., 0.1 “”. S. E denotes standard error, B denote Beta. 
Table 13. OLS for cocoa prices.

\begin{tabular}{lcccc}
\hline & $\mathrm{B}$ & $\mathrm{S} . \mathrm{E}$ & Adj. $\mathrm{R}^{2}$ & $p$-values \\
\hline \multicolumn{2}{c}{ Spot cocoa prices as an outcome variable and } & Futures cocoa prices as a predictor variable \\
\hline Intercept & $8.686 \mathrm{e}-06$ & $9.594 \mathrm{e}-05$ & & 0.928 \\
Futures.cocoa & $9.197 \mathrm{e}-01^{* * *}$ & $5.114 \mathrm{e}-03$ & 0.8741 & $<2 \mathrm{e}-16$ \\
\hline Futures cocoa prices as an outcome variable and Spot cocoa prices as a predictor variable \\
\hline Intercept & $2.131 \mathrm{e}-05$ & $9.753 \mathrm{e}-05$ & & 0.827 \\
Spot.cocoa & $9.504 \mathrm{e}-01^{* * *}$ & $5.284 \mathrm{e}-03$ & 0.8741 & $<2 \mathrm{e}-16$ \\
\hline
\end{tabular}

Significance level is $5 \%$ or $p$-value less than or equals 0.05 , significance codes: 0 “***”, 0.001 “**», 0.01 “*”, 0.05 “”, 0.1 “”. S. E denotes standard error, B denote Beta.

\section{Conclusion and Recommendations}

Using daily data on the log-returns of the series, the researcher estimates the causality and the direction of the causality between selected spot commodity prices and futures prices. Our findings suggest that using OLS, the researcher fails to capture time-varying causality among the estimated parameters and to some extent failed to reject the null hypothesis of no causality between spot prices and futures prices. This problem is solved by the application of the quantile regression approach. In particular, a different shred of relationship and causality emerged from either direction and thus our study agrees with the works (Alzahrani, Masih, \& Al-Titi, 2014; Kaufmann \& Ullman, 2009; Bekiros \& Diks, 2008) that evidenced that there is no systematic impact of futures commodity prices on spot commodity prices. Investors and speculators must take investment positions that protect their holdings and portfolios. The results also provide relevant information on interdependencies among the futures and spot markets and the direction of causality taking time and quantiles into consideration.

\section{Conflicts of Interest}

The author declares no conflicts of interest regarding the publication of this paper.

\section{References}

Ali, J., \& Gupta, K. B. (2011). Efficiency in Agricultural Commodity Futures Markets in India. Agricultural Finance Review, 71, 162-178. https://doi.org/10.1108/00021461111152555

Alzahrani, M., Masih, M., \& Al-Titi, O. (2014). Linear and Non-Linear Granger Causality between Oil Spot and Futures Prices: A Wavelet-Based Test. Journal of International Money and Finance, 48, 175-201. https://doi.org/10.1016/j.jimonfin.2014.07.001

Baker, E., Pham, N. T. A., Daniel, L., \& Bentley, R. (2020). New Evidence on Mental Health and Housing Affordability in Cities: A Quantile Regression Approach. Cities, 96, Article ID: 102455. https://doi.org/10.1016/j.cities.2019.102455

Bekiros, S. D., \& Diks, C. G. (2008). The Relationship between Crude Oil Spot and Futures Prices: Cointegration, Linear and Nonlinear Causality. Energy Economics, 30, 
2673-2685. https://doi.org/10.1016/j.eneco.2008.03.006

Brock, W., Dechert, W., \& Scheinkman, J. (1987). A Test for Independence Based on the Correlation Dimension (Working Paper No. 8702). Madison, United States: Department of Economics, University of Wisconsin.

Chen, A. S., \& Wuh Lin, J. (2004). Cointegration and Detectable Linear and Nonlinear Causality: Analysis Using the London Metal Exchange Lead Contract. Applied Economics, 36, 1157-1167. https://doi.org/10.1080/0003684042000247352

Eide, E., \& Showalter, M. H. (1998). The Effect of School Quality on Student Performance: A Quantile Regression Approach. Economics Letters, 58, 345-350. https://doi.org/10.1016/S0165-1765(97)00286-3

Fama, E. F. (1970). Efficient Capital Markets: A Review of Theory and Empirical Work. The Journal of Finance, 25, 383-417. https://doi.org/10.2307/2325486

Firpo, S., Galvao, A. F., \& Song, S. (2017). Measurement Errors in Quantile Regression Models. Journal of Econometrics, 198, 146-164. https://doi.org/10.1016/j.jeconom.2017.02.002

Fong, W. M., \& See, K. H. (2003). Basis Variations and Regime Shifts in the Oil Futures Market. The European Journal of Finance, 9, 499-513. https://doi.org/10.1080/1351847032000082808

Gil-Alana, L. A., Martin-Valmayor, M., \& Wanke, P. (2020). The Relationship between Energy Consumption and Prices. Evidence from Futures and Spot Markets in Spain and Portugal. Energy Strategy Reviews, 31, Article ID: 100522.

https://doi.org/10.1016/j.esr.2020.100522

Hao, L., \& Naiman, D. Q (2007). Quantitative Applications in the Social Sciences: Quantile Regression. Sage. https://doi.org/10.4135/9781412985550

In, F., \& Kim, S. (2006). The Hedge Ratio and the Empirical Relationship between the Stock and Futures Markets: A New Approach Using Wavelet Analysis. The Journal of Business, 79, 799-820. https://doi.org/10.1086/499138

Inani, K. S. (2018). Efficiency of Indian Agricultural Commodity Futures Market: An Empirical Investigation. Journal of Quantitative Economics, 16, 129-154. https://doi.org/10.1007/s40953-017-0074-7

Junior, P. O., Tiwari, A. K., Padhan, H., \& Alagidede, I. (2020). Analysis of EEMD-Based Quantile-in-Quantile Approach on Spot-Futures Prices of Energy and Precious Metals in India. Resources Policy, 68, Article ID: 101731. https://doi.org/10.1016/j.resourpol.2020.101731

Kaldor, N. (1939). Capital Intensity and the Trade Cycle. Economica, 6, 40-66. https://www.jstor.org/stable/2549077 https://doi.org/10.2307/2549077

Kaufmann, R. K., \& Ullman, B. (2009). Oil Prices, Speculation, and Fundamentals: Interpreting Causal Relations among Spot and Futures Prices. Energy Economics, 31, 550-558. https://doi.org/10.1016/j.eneco.2009.01.013

Kawamoto, K., \& Hamori, S. (2011). Market Efficiency among Futures with Different Maturities: Evidence from the Crude Oil Futures Market. Journal of Futures Markets, 31, 487-501. https://doi.org/10.1002/fut.20479

Kodila-Tedika, O., \& Bolito-Losembe, R. (2014). Poverty and Intelligence: Evidence Using Quantile Regression. Economic Research Guardian, 4, 25-32.

Koenker, R., \& Bassett Jr., G. (1978). Regression Quantiles. Econometrica: Journal of the Econometric Society, 46, 33-50. https://doi.org/10.2307/1913643

Le, T. D., \& Nguyen, D. T. (2020). Capital Structure and Bank Profitability in Vietnam: A 
Quantile Regression Approach. Journal of Risk and Financial Management, 13, 168. https://doi.org/10.3390/jrfm13080168

Lee, C. C., \& Zeng, J. H. (2011). Revisiting the Relationship between Spot and Futures Oil Prices: Evidence from Quantile Cointegrating Regression. Energy Economics, 33, 924-935. https://doi.org/10.1016/j.eneco.2011.02.012

Lian, Y. M., Cheng, C. H., Lin, S. H., \& Lin, J. H. (2019). A Cost of Carry-Based Framework for the Bitcoin Futures Price Modeling. Journal of Mathematical Finance, 9, 42-53. https://doi.org/10.4236/jmf.2019.91004

Mamatzakis, E., \& Remoundos, P. (2011). Testing for Adjustment Costs and Regime Shifts in BRENT Crude Futures Market. Economic Modelling, 28, 1000-1008. https://doi.org/10.1016/j.econmod.2010.11.008

Manogna, R. L., \& Mishra, A. K. (2020). Price Discovery and Volatility Spillover: An Empirical Evidence from Spot and Futures Agricultural Commodity Markets in India. Journal of Agribusiness in Developing and Emerging Economies, 10, 447-473. https://doi.org/10.1108/JADEE-10-2019-0175

Miljkovic, D., \& Goetz, C. (2020). The Effects of Futures Markets on Oil Spot Price Volatility in Regional US Markets. Applied Energy, 273, Article ID: 115288.

https://doi.org/10.1016/j.apenergy.2020.115288

Moosa, I. A. (2002). Price Discovery and Risk Transfer in the Crude Oil Futures Market: Some Structural Time Series Evidence. Economic Notes, 31, 155-165.

https://doi.org/10.1111/1468-0300.00077

Moosa, I. A., \& Al-Loughani, N. E. (1995). The Effectiveness of Arbitrage and Speculation in the Crude Oil Futures Market. The Journal of Futures Markets (1986-1998), 15, 167. https://doi.org/10.1002/fut.3990150205

Pham, T. N., \& Vo, D. H. (2021). Aging Population and Economic Growth in Developing Countries: A Quantile Regression Approach. Emerging Markets Finance and Trade, 57, 108-122. https://doi.org/10.1080/1540496X.2019.1698418

Polanco-Martinez, J. M., \& Abadie, L. M. (2016). Analyzing Crude Oil Spot Price Dynamics versus Long Term Future Prices: A Wavelet Analysis Approach. Energies, 9, 1089. https://doi.org/10.3390/en9121089

Quan, J. (1992). Two-Step Testing Procedure for Price Discovery Role of Futures Prices. The Journal of Futures Markets (1986-1998), 43, 139. https://doi.org/10.1002/fut.3990120203

Samak, N., Hosni, R., \& Kamal, M. (2020). Relationship between Spot and Futures Prices: The Case of Global Food Commodities. African Journal of Food, Agriculture, Nutrition and Development, 20, 15800-15820. https://doi.org/10.18697/ajfand.91.18620

Silvapulle, P., \& Moosa, I. A. (1999). The Relationship between Spot and Futures Prices: Evidence from the Crude Oil Market. Journal of Futures Markets: Futures, Options, and Other Derivative Products, 19, 175-193. https://doi.org/10.1002/(SICI)1096-9934(199904)19:2<175::AID-FUT3>3.0.CO;2-H

Wang, Y., \& Wu, C. (2012). Forecasting Energy Market Volatility Using GARCH Models: Can Multivariate Models Beat Univariate Models? Energy Economics, 34, 2167-2181. https://doi.org/10.1016/j.eneco.2012.03.010

Working, H. (1949). The Theory of Price of Storage. The American Economic Review, 39, 1254-1262. https://www.jstor.org/stable/1816601

$\mathrm{Xu}, \mathrm{X}$. (2018). Causal Structure among US Corn Futures and Regional Cash Prices in the Time and Frequency Domain. Journal of Applied Statistics, 45, 2455-2480. https://doi.org/10.1080/02664763.2017.1423044 
Zavadska, M., Morales, L., \& Coughlan, J. (2018). The Lead-Lag Relationship between Oil Futures and Spot Prices-A Literature Review. International Journal of Financial Studies, 6, 1-22. https://doi.org/10.3390/ijfs6040089

Zhang, Y. J., \& Wang, Z. Y. (2013). Investigating the Price Discovery and Risk Transfer Functions in the Crude Oil and Gasoline Futures Markets: Some Empirical Evidence. Applied Energy, 104, 220-228. https://doi.org/10.1016/j.apenergy.2012.10.066

Zietz, J., Zietz, E. N., \& Sirmans, G. S. (2008). Determinants of House Prices: A Quantile Regression Approach. The Journal of Real Estate Finance and Economics, 37, 317-333. https://doi.org/10.1007/s11146-007-9053-7 